\title{
RETICULOCITOGRAMA EM PACIENTES COM ANEMIA FALCIFORME E HEMOGLOBINOPATIA SC
}

\section{RETICULOCYTOGRAM IN PATIENTS WITH SICKLE CELL ANEMIA AND HEMOGLOBIN SC DISEASE}

\author{
Maguinólia Arai ${ }^{1}$, Railson Henneberg ${ }^{2}$, Aguinaldo José do Nascimento ${ }^{3}$, \\ Juliana Yuka Arai ${ }^{4}$, Paulo Henrique da Silva ${ }^{5}$ \\ ${ }^{1}$ Hospital de Clínica da Universidade Federal do Paraná. \\ 2 Departamento de Patologia Clínica da Universidade Federal do Paraná. \\ 3 Prof. Sênior, Programa de Pós-graduação em Ciências Farmacêuticas, Universidade \\ Federal do Paraná. \\ 4 Acadêmica do Curso de Medicina da Pontifícia Universidade Católica do Paraná. \\ ${ }^{5}$ Departamento de Patologia Clínica da Universidade Federal do Paraná.
}

Recebido para publicação em 11/01/2011

Aceito para publicação em 01/04/2011

\section{RESUMO}

O presente trabalho avaliou, através do reticulocitograma automatizado, obtido em analisador hematológico Sysmex XT 2100, a atividade medular de duas hemoglobinopatias comuns em nosso meio, as hemoglobinopatias SS e SC, em pacientes com idade entre 1 a 14 anos. Os pacientes SS apresentaram atividade medular mais intensa, com contagens mais altas de reticulócitos (média de 17\%) e aumento das frações reticulocitárias mais jovens. Os pacientes SC apresentaram contagens acima do valor de referência, quando comparado com o controle, e perfil das frações reticulocitárias condizente com um quadro hemolítico crônico e discreto. Os resultados encontrados mostram um perfil de reticulocitograma bem característico para cada grupo e permitem que seja feita a diferenciação laboratorial entre anemias de hemólise crônica discreta (SC) e anemias de hemólise crônica intensa (SS). Este trabalho mostra a necessidade de se realizar estudos semelhantes em outras hemoglobinopatias e em doenças eritrocitárias diversas, com a finalidade de se estabelecer um perfil reticulocitário para as patologias hematológicas.

Palavras-chave: Reticulocitograma automatizado. Anemia falciforme. Hemoglobinopatia SC. Anemia hemolítica.

\footnotetext{
ABSTRACT

This work evaluated the erythropoetic behavior of two common hemoglobin SS and SC, using automated reticulocytogram in Sysmex XT 2100, between 1 to 14 years old patients. The group of hemoglobin SS patients showed more intense medullar activity, with higher reticulocytes counting (17\% in average) 
and increase on youngest cell fractions. The SC patients showed high counting in relation to the control group and profile of the reticulocyte fractions congruous of a chronic hemolytic picture, quite different from SS group. The results showed a very characteristic profile in each group and these profiles allowed a laboratory differentiation among the groups. The results are in agreement with other authors, and open perspectives for similar studies, since the knowledge of automated reticulocytogram for the diverse erythrocyte illness is of great clinical importance.

Keywords: Automated reticulocytogram. Sickle cell anemia. Hemoglobin SC. Disease and hemolytic anemia.

\section{Introdução}

O diagnóstico e o estudo das anemias requerem o uso e a interpretação adequada das determinações laboratoriais. Os pré-requisitos para o uso eficiente do laboratório são um histórico e um exame físico cuidadoso, ambos levando às determinações laboratoriais iniciais e fornecendo diretrizes importantes na determinação da natureza da anemia (NELSON; DAVEY, 1995). Os primeiros exames solicitados para o diagnóstico das anemias são o eritrograma e a contagem de reticulócitos.

A contagem de reticulócitos é um importante indicador da capacidade funcional da medula óssea. A reticulocitose indica atividade proliferativa compensatória da medula óssea frente a uma anemia hemolítica, ao passo que uma porcentagem normal ou diminuída, em paciente anêmico, indica uma medula hipoproliferativa ou eritropoese ineficaz. A contagem de reticulócitos avalia, ainda, a atividade da medula óssea após tratamento quimioterápico, radioterapia ou transplante de medula óssea (VAN HOVE; 2000; ZAGO; FALCÃO; PASQUINI, 2004). A determinação do número de reticulócitos pode ser feita por microscopia ótica (contagem manual) ou por método automatizado (NELSON; DAVEY, 1995).

A contagem automatizada de reticulócitos apresenta muitas vantagens sobre a contagem manual porque se baseia na citometria de fluxo e sua exatidão deve-se à intensidade de fluorescência medida, diretamente proporcional à quantidade de grânulos de RNA ribossomal e mensageiro presentes nos reticulócitos. Isto permite que seja feita uma classificação quanto à maturidade dos reticulócitos (TANKE et al., 1983; BRUCE; 1995; LAMCOBE et al., 1999).

A doença falciforme corresponde a um grupo de anemias hemolíticas hereditárias que têm em comum uma alteração estrutural da hemoglobina. A anemia falciforme, que representa a forma homozigota da doença, é caracterizada como uma anemia com hemólise crônica e franca (LOPES, 2006).

A hemoglobinopatia SC caracteriza-se por ser um quadro hemolítico crônico de intensidade discreta e de evolução benigna quando comparada com os pacientes com anemia falciforme (ZAGO; FALCÃO; PASQUINI, 2004).

O presente trabalho teve como objetivo avaliar as diferenças de atividade medular entre os pacientes com hemoglobinopatia SC e SS, pela realização do reticulocitograma em contador automatizado, com análise da contagem relativa e absoluta e das frações reticulocitárias.

\section{Material e métodos}

A amostra foi constituída de pacientes do ambulatório de Hematopediatria da Universidade Federal do Paraná, Curitiba-PR, utilizando as seguintes informações: procedência, faixa etária, sexo e dois meses sem transfusão sanguínea. Não foi avaliado o uso de medicamentos e resultados 
de exames hematológicos. Foram incluídos pacientes com anemia falciforme (SS) e com hemoglobinopatia SC. O eritrograma e a contagem de reticulócitos foram realizados em 56 amostras de sangue periférico colhidos com EDTA-K $\mathrm{E}_{3}$, em crianças com idade entre 1 a 14 anos. Sendo 37 pacientes com genótipo SS e 19 com genótipo SC, os genótipos foram determinados por eletroforese de hemoglobina em acetato de celulose em $\mathrm{pH}$ alcalino e ácido. O grupo controle foi constituído de 25 amostras de crianças sadias.

Tanto o eritrograma como o reticulocitograma foram realizados em contador hematológico Sysmex XT 2100 (Sysmex Corporation, Kobe, Japan). O aparelho efetua a contagem de reticu-lócitos por citometria de fluxo utilizando como corante a polimetina e tecnologia a laser de íon argônio.
Os exames analisados no eritrograma foram: eritrócitos (RBC); volume globular (VG); hemoglobina (HB); volume corpuscular médio (VCM); e índice de variação do tamanho dos eritrócitos (RDW). O reticulocitograma analisou a contagem relativa; contagem absoluta; fração reticulocitária imatura (IRF); reticulócitos com baixa fluorescência (LRF); reticulócitos com média fluorescência (MFR); e reticulócitos com alta fluorescência (HRF).

\section{Resultados}

A Tabela 1 mostra os valores hematológicos médios de crianças do sexo masculino e feminino com hemoglobinopatia SS, SC e o grupo controle normal.

Tabela 1 - Valores hematológicos médios de crianças do sexo masculino e feminino com hemoglobina SS, SC e normal.

(continua)

\begin{tabular}{ccccccc}
\hline Grupo & \multicolumn{2}{c}{ SS } & \multicolumn{2}{c}{ SC } & Normal \\
\hline Sexo & M & F & M & F & M & F \\
\hline RBC & $2,57(0,62) \#$ & $2,61(0,49) \$$ & $4,45(0,79)$ & $4,47(0,56)$ & $4,58(0,27) \#$ & $4,64(0,28) \$$ \\
\hline HB & $7,53(1,01) \#$ & $7,89(1,04) \$$ & $9,94(0,96) \#$ & $10,99(1,44) \$$ & $13,13(0,76) \#$ & $13,26(0,83) \$$ \\
\hline VG & $22,45(2,57) \#$ & $23,39(3,27) \$$ & $27,72(1,64) \#$ & $30,16(3,43) \$$ & $37,85(1,89) \#$ & $38,56(2,12) \$$ \\
\hline VCM & $88,81(10,79) \#$ & $87,02(14,47$ & $64,32(14,02) \#$ & $67,92(6,76) \$$ & $81,72(3,18) \#$ & $82,01(3,24) \$$ \\
\hline RDW & $24,42(5,33) * \#$ & $20,43(2,44) * \$$ & $20,14(3,99)$ & $18,43(2,29) \$$ & $13,12(0,72) \#$ & $13,04(0,63) \$$ \\
\hline RET (\%) & $17,17(4,86) \#$ & $17,15(5,51) \$$ & $3,67(1,97) \#$ & $3,29(1,29)$ & $0,83(0,29) \#$ & $0,82(0,32) \$$ \\
\hline RET (N) & $0,44(0,13) \#$ & $0,43(0,14) \$$ & $0,15(0,06) \#$ & $0,14(0,04) \$$ & $0,04(0,01) \#$ & $0,04(0,01) \$$ \\
\hline IRF (\%) & $45,91(11,77) \#$ & $38,16(12,09) \$$ & $30,28(4,07) * \#$ & $21,23(4,45) * \$$ & $5,69(2,95) \#$ & $5,01(2,41) \$$ \\
\hline IRF (N) & $1,18(0,41$ & $0,99(0,34$ & $1,32(0,11) *$ & $0,95(0,30) *$ & - & - \\
\hline
\end{tabular}




\begin{tabular}{ccccccc}
\hline Grupo & \multicolumn{2}{c}{ SS } & \multicolumn{2}{c}{ SC } & Normal \\
\hline Sexo & M & F & M & F & M & F \\
\hline LFR (\%) & $52,10(9,9) 2^{* \#}$ & $59,65(7,35)^{*} \$$ & $69,72(4,07) \#$ & $78,77(5,49) \$$ & $94,31(2,95) \#$ & $95,00(2,42) \$$ \\
\hline LFR (N) & $1,35(0,45$ & $1,56(0,34$ & $3,12(0,72)^{*}$ & $3,51(0,46)^{*}$ & - & - \\
\hline MRF (\%) & $39,77(8,37)^{* \#}$ & $33,23(5,83) * \$$ & $25,42(3,65)^{* \#}$ & $17,84(4,29)^{*} \$$ & $5,20(2,63) \#$ & $4,64(2,30) \$$ \\
\hline MRF (N) & $1,01(0,30$ & $0,86(0,19$ & $1,11(0,07)^{*}$ & $0,80(0,24)^{*}$ & - & - \\
\hline HFR (\%) & $8,13(1,84) \#$ & $7,08(1,61) \$$ & $4,78(0,85) \#$ & $3,38(1,55) \$$ & $0,49(0,69) \#$ & $0,37(0,48) \$$ \\
\hline HFR (N) & $0,21(0,08)$ & $0,18(0,05)$ & $0,21(0,04)$ & $0,15(0,07)$ & - & - \\
\hline
\end{tabular}

* - Diferença estatisticamente significante entre sexo (anova $p<0,05)$;

\# - Diferença estatisticamente significante Vs. Normal para sexo masc. (anova $\mathrm{p}<0,05$ );

$\$$ - Diferença estatisticamente significante Vs. Normal para sexo fem. (anova $p<0,05$ );

- Não analisado.

$\mathrm{RBC}$ - contagem de eritrócitos $\left(/ \mathrm{mm}^{3}\right)$;

$\mathrm{HB}$ - dosagem de hemoglobina $(\mathrm{g} / \mathrm{dl})$;

$\mathrm{VG}$ - volume globular (\%);

VCM - volume corpuscular médio (fl); e RDW (red cell distribution width, \%);

RET - contagem de reticulócitos;

IRF - fração reticulocitária imatura;

LRF - reticulócitos com baixa fluorescência;

MFR - reticulócitos com média fluorescência;

HRF - reticulócitos com alta fluorescência;

$\%$ - Contagem relativa;

$\mathrm{N}$ - contagem absoluta.

Os dados representam média (desvio-padrão).

\section{Discussão}

A classificação morfológica da anemia falciforme é normocítica e normocrômica e a fisiológica é hemolítica, com hemólise intra e extravascular (CORRONS, 1994). O eritrograma dos pacientes SS apresentou-se normocítico (VCM com média de $88 \mathrm{fl}$ ), com contagens de eritrócitos e concentração de hemoglobina menores do que o grupo com hemoglobinopatia SC. As médias destes parâmetros são estatisticamente diferentes entre os dois grupos estudados $(p<0,05)$.

$\mathrm{O}$ número de eritrócitos no grupo $\mathrm{SS}$ foi quase $50 \%$ mais baixo do que nos pacientes SC. Isto pode ser explicado devido à hemólise severa que ocorre nos pacientes SS, uma vez que a vida média dos eritrócitos afoiçados está entre 10 e 30 
dias (BENSINGER; GILLETTE, 1974). A vida média dos eritrócitos nos pacientes SC é de 18 a 56 dias, significativamente superior (WILLIAM; WILLIAMS, 1976).

O estudo realizado mostrou que o VCM está dentro de valores normocíticos podendo chegar à macrocitose, que pode ser explicada pelo aumento da fração reticulocitária de alta fluorescência, composta por reticulócitos imaturos e com maior volume que os eritrócitos. A microcitose encontrada no grupo SC é, provavelmente, uma consequência da desidratação da célula (perda de $\mathrm{K}+$ e água), a qual decorre da interação da HbSC com a membrana celular (possivelmente na banda 3), aumentando, de algum modo, o efluxo do $\mathrm{K}+$. Em decorrência disso ocorre o encolhimento da célula, classificada morfologicamente como xerócito (BALLAS et al., 1987). Esses resultados foram compatíveis com dados anteriormente publicados, onde o VCM dos portadores de $\mathrm{Hb}$ SC é menor (em média 10 a 15 fl) (WANG, 2009).

O grupo SC demonstrou um perfil reticulocitário com predomínio de reticulócitos com baixa fluorescência, revelando menor atividade medular. A hemoglobinopatia SC, por ser caracterizada como um estado hemolítico crônico e discreto, permite que a medula óssea estabeleça um equilíbrio entre a produção e a destruição, e a doença cursa sem manifestação clínica significativa. A cristalização da hemoglobina C, in vivo, somente acontece em condições raras e especiais, e sua intensidade não altera de maneira significativa a meia-vida eritrocitária (CORRONS, 1994), o que explica os resultados encontrados neste trabalho em relação ao número de eritrócitos e de reticulócitos. Outra possível explicação está correlacionada com a solubilidade da mistura da deoxi-HbS e $\mathrm{HbC}$, que não é diferente do traço falciforme (AS). A atividade medular na hemoglobinopatia SC demonstra uma capacidade funcional semelhante à encontrada em portadores do traço falcêmico (WANG, 2009). McCurdy
(1962) descreve a doença SC como uma anemia hemolítica crônica, com níveis de hemoglobina entre 10 e $13 \mathrm{~g} / \mathrm{dL}$, contagens de reticulócitos entre 3 e $10 \%$. É importante destacar que a variação encontrada no estudo de McCurdy pode ser explicada pela metodologia empregada para a contagem de reticulócitos, pois existem diferenças entre o método manual e o automatizado.

Estudos eritrocinéticos demonstram uma atividade medular de quatro a cinco vezes maior nos pacientes com hemoglobinopatia SS (McCURDY, 1969). As frações de alta fluorescência, no trabalho realizado, confirmam a maior atividade da medula óssea no grupo SS quando comparado ao grupo SC. O que caracteriza, no grupo SS, um processo hemolítico intenso, devido provavelmente à propriedade reológica da célula falciforme (WANG, 2009).

Os resultados apresentados demonstram uma clara diferença da atividade eritropoética entre os dois grupos, o que pôde ser evidenciado tanto pela contagem quanto pela análise das subpopulações reticulocitárias. Tanto o grupo SS como o SC apresentam contagem reticulocitária aumentada e estatisticamente significativa em relação ao grupo controle. A introdução das contagens automatizadas de reticulócitos nos laboratórios clínicos é uma tendência porque a contagem manual não tem a mesma exatidão e não permite a classificação das frações reticulocitárias. O entendimento do reticulocitograma é de fundamental importância para o diagnóstico, caracterização e acompanhamento das anemias hemolíticas. Os pacientes com hemoglobina SS, neste estudo, estavam fora da crise de falcização e ficou estabelecido o perfil reticulocitário para eles. Se o perfil reticulocitário se intensificar, e se houver aumento da contagem de reticulócitos e das frações imaturas e de alta fluorescência dos reticulócitos, ele indica que o paciente está entrando em crise de falcizalção. Atualmente, os bancos de sangue que atendem pacientes falcêmicos têm no protocolo dos exames laboratoriais a contagem 
de reticulócitos. O ideal é que esta contagem seja feita de modo automatizado, já que pelo método manual não é possível fazer a classificação das frações reticulocitárias e o erro da contagem manual é muito elevado: o coeficiente de variação é de 33,9\% (SILVA; HASHIMOTO; ALVES, 2009).

É importante salientar que estudos semelhantes devem ser realizados em outras anemias, com a finalidade de estabelecer o perfil reticulocitário em cada uma delas.

\section{REFERÊNCIAS}

BALLAS, S. K.; LARNER, J.; SMITH, E. D.; SURREY, S.; SCHWARTZ, E.; RAPPAPOT, E. F. The xerocytosis of Hb SC disease. Blood, USA, v. 1, p. 124-130, Jan 1987.

BENSINGER, T. A.; GILLETTE, P. N. Hemolysis in sickle cell disease. Arch. Intern. Med. v.133, p.595-606, 1974.

BRUCE, H.; OMVOLD, K.; BIGELOW, N. C. Flow cytometric reticulocyte maturity index: a useful laboratory parameter of erythropoietic activity in anemia. Cytometric., v. 11. p. 35-39, 1995.

CORRONS, J. L. V. Hematologia clinica. 3.ed. Madrid: Mosby/Doyma Libros, 1994.

LAMCOBE, F.; LACOSTE, L.; VIAL, J. P.; BRIASIS, A.; REIFFERS, J.; BOISSEAU, M. R.; BERNARD, P. Automated reticulocyte counting and immature reticulocyte fraction measurement. American Journal Clinical Pathology, USA, v. 112, p. 677-666, 1999.

LOPES, A. C. Tratado de clinica médica. São Paulo: Roca, 2006.

McCURDY, P. R. 32-DFP and 51-Cr for measurement of red cell life span in abnormal hemoglobin syndromes. Blood, v.32, n.2, p.214-224, 1969.

. Erythrokinetics in abnormal hemoglobin syndromes. Blood, v.20, n.686, 1962.

NELSON, A. D.; DAVEY, F. R. Doença dos eritrócitos. In: HENRY, J. B. Diagnóstico clínicos \& tratamento- por métodos laboratoriais. 18.ed. Barueri: Manole, 1995.

SILVA, P. H.; HASHIMOTO, Y.; ALVES, H. B. Hematologioa laboratorial. Rio de Janeiro: Revinter, 2009.

TANKE, H. J.; ROTHBARTH, P. H.; VOSSE, J. M. J. J.; KOPER, G. J. M.; PLOEM, J. S. Flow cytometric of reticulocytes applied to clinical hematology. Blood, USA, v. 61, p. 1091-1097, 1983.

ZAGO, M. A.; FALCÃO, R. P.; PASQUINI, R. Hematologia: fundamentos e práticas. São Paulo: Atheneu, 2004.
VAN HOVE, L.; SCHISANO, T.; BRACE, L. Anemia diagnosis, classification, and monitoring using cell dynb technology reviewed for the new millennium. Laboratory Hematology, USA; v.6, p.93-108, 2000.

WANG, W. C. Wintrobe's clinical hematology. 12.ed. Philadelphia: Lippincott Willians \& Wilkins, 2009. v.1

WILliam, J.; WILliamS, M. D. Hematologia. Rio de Janeiro: Guanabara Koogan, 1976. 